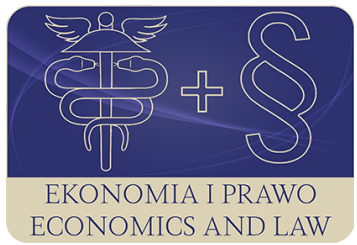

EKONOMIA I PRAWO. ECONOMICS AND LAW

Volume 17, Issue 2, June 2018

p-ISSN 1898-2255, e-ISSN 2392-1625

www.economicsandlaw.pl

ORIGINAL ARTICLE

received 13.06.2017; revised 24.03.2018; accepted 30.06.2018

Citation: Przybyłowski, A. (2018). Sustainable urban mobility planning: Gdynia city case study.

Ekonomia i Prawo. Ecomomics and Law, 17(2): 195-209.

doi:10.12775/EiP.2018.014.

\title{
Sustainable urban mobility planning: Gdynia city case study
}

\author{
ADAM PRZYBYŁOWSKI \\ Gdynia Maritime University, Faculty of Entrepreneurship and Quality Science, Department \\ of Economy and Economic Policy, ul. Morska 81-87, 81-255 Gdynia, Poland \\ $\square$ a.przybylowski@wpit.am.gdynia.pl
}

\begin{abstract}
Motivation: Sustainable urban development is the current global priority; however, most cities lack the capacity and resources to ensure that the city develops in a sustainable manner. Mobility is one of the most difficult topics to face in metropolitan large areas. It involves both environmental and economic aspects, and needs both high technologies and virtuous people behaviours. Dynamical urban development and inhabitants lifestyle changes, especially in the heavy congested port agglomerations, result in a continuous increase of their transport needs. As transport behaviours change, the number of vehicles on streets grows resulting in congestion, an increased number of accidents, exhaust and noise emissions and, consequently, a lowered quality of life. Thus a sustainable approach to urban mobility and transport planning is becoming increasingly common in all EU countries. The study is based on the literature sources analysis and survey research results obtained with a questionnaire for stakeholders to assess particular areas and activities related to mobility issues.
\end{abstract}

Aim: The aim of the paper is to present the urban sustainable development challenges, taking as a case study the Sustainable Urban Mobility Plan (SUMP) elaboration process selected issues in the city of Gdynia within the CIVITAS DYN@MO being a European project implemented under the CIVITAS II PLUS initiative (funded from the 7th Framework Programme of the European Commission).

Results: It is quite a challenge to ensure a sustainable urban mobility pattern which requires a high level of stakeholders' participation and establishing a detailed complex planning process. Key stakeholders of Gdynia, representing the public administration sector, the transport market and university researchers (including the author), included in the planning process earlier, invited to the assessment gave the highest priority to the tariff and ticket integration in the Metropolitan Area, parking issues, the inclusion 
of pedestrian traffic in project planning and public spaces. The promotion among inhabitants and students or city bicycle system were given a medium priority and the lowest was given to carpooling, environmental-friendly vehicules and such mobility management tools as Mobility centre or the Officer for Mobility.

Keywords: mobility planning; urban sustainable development; city of Gdynia JEL: 018

\section{Introduction}

The idea of sustainable development makes the basis for a new thinking about civilization and strikes fundamental aspects of to-date human activity. It assumes the rejection of the present model of development chiefly focused on pursuing infinite economic growth; therefore it requires a transformation of consciousness in the direction of perceiving the relationship and harmony between economic, human and social values and their interdependence with nature. Mobility is one of the most difficult topics to face in metropolitan large areas. It involves both environmental and economic aspects, and needs both high technologies and virtuous people behaviours. Dynamical urban development and inhabitants lifestyle changes result in a continuous increase of their transport needs. As transport behaviours change, the number of vehicles on streets grows resulting in congestion, an increased number of accidents, exhaust and noise emissions and, consequently, a lowered quality of life. Thus, a sustainable approach to urban mobility and transport planning is becoming increasingly common in all EU countries The purpose of the article is to present the urban sustainable development challenges, taking as a case study the Sustainable Urban Mobility Plan (SUMP) elaboration process in the port city of Gdynia within the CIVITAS DYN@MO project.

\section{Literature review}

The sustainable development of the cities represents a major challenge for the future of the planet in the 21st century, relatively to the contribution and adaptation to climate change, natural resources consumption, energetic transition (the 'after oil' transition), population mobility, welfare and security, pollution, the global economic growth (Ducruet, 2011). Within the United Nations Human Settlements Programme works on a new development model under the slogan 'The city we need' are being carried out. Urban centres should: integrate their community, close the material and energy flow, stimulate the economy and involve citizens in it, strengthen the identity and sense of belonging, provide security, health, be inexpensive in everyday use and provide a just access to its resources, and be governed at metropolitan level (UN-Habitat, 2017).

For historical reasons, a great part of the cities, are located on a coast or on a river, thus including a port and playing a special and major role in the national and the global economy (nodes of logistic chain, concentration of popu- 
lation, touristic attractiveness). The integrated planning for cities development has to consider the passengers' mobility and the transport of goods as priorities to reach a sustainable growth (Morel, 2013). "Cities are evolving faster than ever and encountering unprecedented demographic, environmental, economic and social challenges. Sustainable urban development is the current global priority; however, most cities lack the capacity and resources to ensure that the city develops in a sustainable manner (Schubert, 2011, pp. 54-69). Multistakeholder cooperation is essential to fill this gap and build transformation strategies to better shape urbanization outcomes and lead cities towards growth, well-being and prosperity for all (Zopf, 2017).

Here, green industrial activities, able to decouple economic wealth production from ecological losses, should be grounded while considering the model of living systems (Boulos, 2016). Port city, which serves as a link between the local economy and the global economy, is an interaction of both urban and port systems, giving rise to its complex and dynamic nature (Hein, 2011). While the development of a port city is an aspect that requires continual research and monitoring, the current literature addressing the issue of sustainable development in port cities is rather limited (Girard, 2013). In addition, empirical studies often analyse the port system and the urban system separately, with little research attempting to integrate the two systems.

The growing number of usage disputes over increasingly coveted coastal areas is prompting local managers to incorporate urban and port-related issues in overarching planning programs (Xiao \& Siu Lee Lam, 2017, pp. 255-262). For example, planning of the sea front and the buffer zone between the port and the city must contribute decisively to the deployment of more effective, cleaner transport services for the port city as a whole (Boulos, 2016). In general, one of the key global challenges for planners and decision-makers consists in integrating sustainable development goals (environmental and social components, as well as the stimulation of industrial competitiveness) into urban planning (Przybylowski, 2017).

Thus, a new approach to management of city investments is needed. It has been established including the principles of sustainable smart development, triad of creativity - circularisation - synergy, stakeholder theory, and the idea of social-business responsibility. The approach primarily elevates the concept of the public governance which is characterised by a de-centralisation, participation, constructivist and a win-win approach. These attributes increasingly refer to the decision-making process and subsequent implementation. The city development/re-development management relates to use of scares resources and transformation of the existing state to desired one (Wojewnik-Filipkowska, 2017, pp. 79-90). The management relates to economic, social, technologi$\mathrm{cal}$, and natural systems. The city development and investment management means space management as city is both a physical place of paths and buildings, and also a space of values, beliefs, and relations. The general aim of the city development management is to ensure sustainable development which is man- 
ifested by an increase in national income, qualitative changes in the structure of the economy, availability of goods and services for citizens, better standard of living. But translating this concept into action is a challenge. On the strategic level the management means outlining goals at future requirements. It is master planning on the tactical level, and finally, planning, implementation, and evaluation of urban development project on the operational level (Girard, 2010).

It is noteworthy that the urbanisation is to be an area of significant civilizational changes, as the future of humankind is linked with cities. No more than $5 \%$ of the world population lived in the cities in 18th century, while today it is more than $50 \%$, and United Nations forecasts that more than $80 \%$ of the population will live in urban area by the end of this century (United Nations, 2014). In the European Union more than $60 \%$ of the population lives in urban areas. Almost $85 \%$ of European Union GDP is generated there. Cities boost the economy, attract investors, new jobs are established there; that is why cities play an important role in the economy. Transport produces $40 \%$ of $\mathrm{CO}_{2}$ emission and $70 \%$ of other pollution emissions in cities (Brdulak \& Brdulak, 2017). Because of this phenomenon the European economy incurs losses, nearly EUR 100 billion, which translates into about $1 \%$ of GDP. The data confirms the assumptions that contemporary cities are facing a challenge related to keeping the balance of resources and strengthening development which would improve security and the quality of life for citizens.

Also, in contemporary cities the quality of life greatly depends on the efficient transport system (The City of Copenhagen, 2015). The efficiency of goods and people mobility in urban traffic is not only determined by reliable services but most of all by time and mobility efficiency which today determine the way many users of urban traffic live. The constantly changing lifestyle of people living in cities, the need for increased mobility and efficient mobility of goods caused that current transport systems are not able to counter issues such as congestion, noise, pollution or accidents involving pedestrians (Burns, 2013). Urban mobility, in accordance with the principles of sustainable development, is important not only for the city but also for its citizens (Banister, 2008). It influences the development of the global society, which is being increasingly concentrated in urban agglomerations (Studzieniecki, 2016, pp. 235-241). Due to the depleting natural resources of cheap fossil fuels, it seems natural to seek alternative, non-motorised means of transport across urban areas (Kim, \& Dumitrescu, 2010).

Some scientists (Jason Chang \& Hsu, 2014) identify seven most important factors in achieving greener and more sustainable mobility, and chart their relationship in the eco-mobility equation (1):

$$
E M=[(T D+A M+T M+G T+I P) \cdot S] \cdot L .
$$

$E M$, or the effectiveness of implementing eco-mobility, may be manifested as the reduction of travel delays, emissions, and accident rates. Equation (1) identifies a horizontal relationship between five key eco-mobility strategies, while 
recognising the exponential potential of both stakeholders $(S)$ and leadership $(L)$. The five key eco-mobility strategies are:

- TD - transit-oriented development;

- AM - active mobility (non-motorized transportation);

- $T M$ - transport management;

- GT - green transport (BBMW policy);

- IT — integrated pricing schemes.

These five horizontal elements can be understood as the "push and pull' factors between motorized vehicles, public transport and non-motorized transport modes. However, the successful fulfilment of these eco-mobility strategies is exponentially influenced by the involved stakeholders and leadership. Therefore, the behaviour of stakeholders, $S$, in the proposed equation indicates the importance of how the interests between different stakeholders are coordinated, as eco-mobility related projects usually involve certain levels of Public-Private Partnership (PPP). The private sector is generally considered more efficient and flexible in attaining project objectives that are not necessarily consistent with public interests. The behaviour of stakeholders has to be shaped based on well-defined objectives of EM implementation, which maximize the benefits of both sectors, thereby motivating reasonable efforts to pursue common and respective interests (Jason Chang \& Hsu, 2014).

Above all, leadership, $L$, is the key factor, albeit abstract, for how an eco-mobility related project can be implemented, especially for many developing countries that are currently undergoing different stages of social development and reformation. Both the government and citizens may still be learning to balance the conflicts between various aspects of social development. Studies from theoretical and practical perspectives have extensively discussed the traits required for a leader. In the context of eco-mobility in developing cities, leadership may translate into holistic vision, systematic thinking, inspiring resolution, and a willing heart to listen to and understand the needs from different perspectives of a society (Jason Chang \& Hsu, 2014). Both $S$ and $L$ are located as the exponents in the proposed equation, which specifies their decisive effects. Leadership and a well-coordinated relationship between stakeholders can trigger strong momentum in changing traveller behaviour towards greener transportation and social development, resulting in an effective implementation of eco-mobility beyond expectation. Only based on an understanding of traveller behaviour in response to the implemented strategies, is it possible to evaluate and adapt eco-mobility strategies to improve their effective implementation and to further educate travellers. Moreover, the investigation of an eco-mobility cannot be separated from the context of land-use modelling - which represents local features - or without knowing the city's historical course of development.

The need for more sustainable and integrative planning processes as a way of dealing with the complexity of urban mobility has been widely recognised. New approaches to urban mobility planning are emerging as local authorities 
seek to develop strategies that can stimulate a shift towards cleaner and more sustainable transport modes (table 1).

Typical stakeholder groups involved in transport projects have been presented on table 2. Identifying urban mobility stakeholders and understanding their potential role and position in the process is important to achieve the overall goals of sustainable urban mobility planning.

\section{Methods}

The study is based on the literature sources analysis and survey research results obtained with a questionnaire for stakeholders. To determine the most desirable directions of activity in the field of mobility in Gdynia, a questionnaire was addressed to the stakeholders in order to assess particular areas and activities. Key stakeholders of Gdynia, related to mobility issues, involved in the planning process earlier, representing primarily the public administration sector, the transport market and university researchers (including the author) were invited to the assessment. Every activity was subject to assessment in a $\mathrm{C}-\mathrm{A}++$ scale.

\section{Results}

The Sustainable Urban Mobility Plan (SUMP) is a concept which contributes to achieving EU objectives on climate and energy. The new European Commission's planning concept proposals treats challenges related to transport in a more sustainable, integrate and comprehensive way (Wefering et al., 2013). It focuses on involving stakeholders, coordinating the vision between social and economic sectors (land management, transport, social policy, safety, health, etc.) as well as between authorities. It requires a sustainable, long-term vision of urban area, taking into account broader costs and social benefits. Its aim is to meet the mobility needs of people and companies. It proposes actions improving the quality of life.

The 2013 Urban Mobility Package sets out a concept for Sustainable Urban Mobility Plans (SUMPs) that has emerged from a broad exchange between stakeholders and planning experts across the European Union. The concept describes the main features of a modern and sustainable urban mobility and transport plan. All over Europe, cities are engaging in bringing such a plan together (Polis Network, 2016). Ten main arguments for this approach are (Wefering et al., 2013):

- improving quality of life;

- saving costs - creating economic benefits;

- contributing to better health and environment;

- making mobility seamless and improving access;

- making more effective use of limited resources;

- winning public support; 
- preparing better plans;

- fulfilling legal obligations effectively;

- using synergies, increasing relevance;

- moving towards a new mobility culture.

Consequently, SUMP is a document that covers the urban and suburban areas (the functional area), defines the passenger public transport, non-motorised transport, intermodality, road transport, mobility management, use of Intelligent Transportation Systems (ITS), urban logistics, city road traffic safety, implementation of new use patterns or promotion of clean and energy-saving vehicles (clean fuels and vehicles), considering the related needs identified in the given area.

The European Commission indicates certain stages of preparation of the Sustainable Urban Mobility Plan (SUMP), namely (Wefering at al., 2013):

- definition of potential, i.e. a verification to what extent sustainable development principles are in accordance with current political priorities and to what extent they are already part of the city development policy;

- definition of the scope of the plan, i.e. on the one hand the definition the territory, for which it is developed, and on the other hand, of the appropriate authorities and institutions to make decisions, also financial, and approve activities;

- situation analysis and scenario development to support a transparent and rational establishment of the objectives to pursue;

- definition of a common vision, which constitutes a qualitative description of the desired future of the city and must place transport and mobility in the wider context of economic and social development;

- definition of priorities and measurable objectives (as the vision is an important qualitative description of the desired future, so the nature of the expected changes must be described through specific, measurable objectives to be defined in detail before the activities begin — as methods of achieving the objectives);

- preparation of effective sets of actions is fundamental to sustainable mobility planning, because only if properly selected and efficiently implemented, they can ensure the fulfilment of the assumed objectives (the selection of activities must be consulted with main stakeholders, cost effective and aligned with the good practices of other cities);

- definition of the scope of responsibilities and budget allocation - strictly connected with the selection of activities;

- monitoring and assessment, both during the planning process and activity implementation, are essential to the implementation of the activities included in the Plan;

- adoption of the Sustainable Urban Mobility Plan — as another stage, confirming the political will to complete the objectives included therein; 
- the implementation phase - begins upon the Plan acceptance (at this stage the working plan performance should be enforced, e.g. through various agreed and unified reporting forms);

- monitoring and conclusions from assessment - allowing regular plan updates.

The main idea behind sustainable urban mobility plans is to work towards the creation of a sustainable urban transport system through the achievement of objectives like: transport safety improvement, transport environmental impact reduction, passenger and goods transport efficiency and effectiveness improvement, urban area attractiveness and quality improvement and improvement of transport services accessibility for inhabitants. The scope of mobility planning covers all types and forms of transport in the city, including public and private transport, passenger and goods transport, as well as motorised and non-motorised transport. The Plan preparation and implementation process involves various groups of entities, characterised by e.g. a participative approach, a long-term vision and a clear action plan, aimed at a sustainable and integrated development of all forms of transport, as well as a regular monitoring of Plan implementation (Lopez-Ruiz et al., 2013).

Under the European project entitled CIVITAS DYN@MO (DYNamic citizens @ctive for sustainable MObility) within the CIVITAS II PLUS initiative, funded from the 7th Framework Programme of the European Commission, the Sustainable Urban Mobility Plan (SUMP) has been elaborated and adopted by the Gdynia city authorities. The plan takes into account the principles of participation, integration and assessment as well as be based on current practices of urban mobility planning.

Gdynia is an important European transport node with maritime connections to ports in Europe and worldwide. It is an important component of the GdańskGdynia-Sopot Metropolitan Area (GGS MA) being the most important metropolitan in North Poland and simultaneously in the South Baltic Sea with a regional yet international influence. Gdynia is a city with a population of almost 250,000 and the area of $135 \mathrm{~km}^{2}$ in the Pomorskie Voivodeship. Some objectives of sustainable transport development cannot be achieved without clearly setting Gdynia in the metropolitan area and in the Pomorskie Voivodeship. This is related to the numerous metropolitan functions and the role of the port and the shipbuilding industry located in the city. In the urban area, complex relations are formed at the interface of environment, society and economy. A dynamic development of seaports (in particular container terminals) has become an important factor stimulating the economic development. The dynamic development of Gdynia and the accompanying changes in spatial development, connected with the intensification of suburbanisation processes create transport problems that have an impact on the public space, inhabitants quality of life and environment. The most important problems include increasing congestion, resulting in a reduced travel speed, domination of passenger cars in trips, negative transport patterns and behaviours among the inhabitants, strengthened by 
uncontrolled suburbanisation processes and settlement development in neighbouring communes.

To assess transport operation and the aspects of transport planning in the city, the assessment form was used, which was developed under the ADVANCE EU project (a three-year project co-financed from the Intelligent Energy - Europe programme and implemented by 11 partners in 8 European cities in 2011-2014). The ADVANCE project assessment form contains a set of questions in the area of mission and activity. The mission area relates to the process of planning (e.g. co-operation issues, inhabitants inclusion, use of evaluation), while the activity area concentrates on eight subject areas, such as parking policy, urban spatial development, pedestrian traffic, bicycle traffic, goods transport, car traffic, mobility management and goods transport.

The self-assessment process included stakeholders representing primarily the public administration sector (City Hall, police, public transport authority, etc.) and the transport market (transport operators, etc.) and NGO's. The overall result of the city in a 1-4 scale (corresponding to activity levels) was 2.06, which means that in a general assessment Gdynia's transport policy implementation is process-oriented, while systemic activities are implemented to a small or medium extent. The detailed self-assessment results are available in the self-assessment report for the purposes of preparing the SUMP for Gdynia (Mobilna Gdynia, 2017).

To determine the most desirable directions of activity in the field of mobility in Gdynia, a questionnaire was addressed for stakeholders to assess particular areas and activities (Wolek, 2016). Key stakeholders of Gdynia, related to mobility issues, involved in the planning process earlier, representing primarily the public administration sector, the transport market and university researchers (including the author) were invited to the assessment. Every activity was subject to assessment in a $\mathrm{C}-\mathrm{A}++$ scale:

- $\mathrm{C}$ - these activities should not be in focus - they are unnecessary or already implemented to a sufficient extent in Gdynia;

- B - it is not necessary at the moment, but to be considered for implementation in the future (after 2025);

- A - it is necessary to concentrate on the completion of this activity, however the $\mathrm{A}, \mathrm{A}+$ and $\mathrm{A}++$ symbols determine the priority (where $\mathrm{A}++$ is the highest possible extent).

Prioritisation results are shown in table 3. The highest priority was given to the tariff and ticket integration in the Metropolitan Area, parking issues, the inclusion of pedestrian traffic in project planning and public spaces.

The lowest priority was given to carpooling, environmental-friendly vehicules and such mobility management tools as Mobility centre or the Officer for Mobility. The promotion among inhabitants and students or city bicycle system were given a medium priority. Based on the obtained survey results and the direct consultation meetings with key stakeholders, strategic objectives of the SUMP for Gdynia and political challenges have been elaborated (table 
4). Those 4 strategic objectives have been defined to enable implementation of the sustainable mobility vision until 2025.

\section{Conclusion}

As growing economies heavily rely on fossil fuels and unconstrained emission, it is critical to begin adopting strategies that balance this skewed development and return to a more sustainable course. Mobility planning in modern agglomerations, in particular for port cities with huge traffic density and congestion problems, is a complicated task because of complex and contradictory factors and needs in this process. Political and financial issues pose additional difficulty. Current modal split, the inability of most coastal cities to absorb rapidly expanding port developments and population growth, may compound both environmental and health problems for the inhabitants. Also, it is quite a challenge to ensure a sustainable urban mobility pattern which requires a high level of stakeholders' participation and establishing a detailed complex planning process.

Based on the strategic framework for the development of port city Gdynia, the Sustainable Urban Mobility Plan (SUMP) has been elaborated stating the vision of the transport system and mobility improvement till 2025. Practically from the beginning, the SUMP preparation process included stakeholders the institutions, units, companies and education sector (schools and universities) of Gdańsk. The main work group included the representatives of: Zarząd Dróg i Zieleni in Gdynia, the University of Gdańsk, the Gdańsk University of Technology and Public Transport Authority of Gdynia. The remaining stakeholders were included through direct meetings, email correspondence, workshops, marketing surveys, direct interviews, electronic surveys and consultations, related both to the SUMP and to the individual potential activities (e.g. pedestrian zones, the vision of the plan, transport behaviour and preference of the inhabitants of Gdynia).

Key stakeholders of Gdynia, included in the planning process earlier, invited to the assessment gave the highest priority to the tariff and ticket integration in the Metropolitan Area, parking issues, the inclusion of pedestrian traffic in project planning and public spaces. The lowest priority was given to carpooling, environmental-friendly vehicles and such mobility management tools as Mobility centre or the Officer for Mobility.

\section{References}

Banister, D. (2008). The sustainable mobility paradigm. Transport Policy, 15(2). doi:10.1016/j.tranpol.2007.10.005.

Boulos, J. (2016). Sustainable development of coastal cities-proposal of a modelling framework to achieve sustainable city-port connectivity. Procedia Social and Behavioral Sciences, 216. doi:10.1016/j.sbspro.2015.12.094. 
Brdulak, A., \& Brdulak, H. (Eds.). (2017). Happy city: how to plan and create the best livable area for the people. Cham: Springer International Publishing. doi:10.1007/978-3-319-49899-7.

Burns, L.D. (2013). Sustainable mobility: a vision of our transport future. Nature, 497(7448). doi:10.1038/497181a.

Ducruet, C. (2011). Economic development paths of port-cities: specialization vs. diversification. Paper presented at the Global ports and urban development: challenges and opportunities, OECD Workshop, Paris.

Girard, L.F. (2010). Creative evaluations for a human sustainable planning. In M. Cerreta, G. Concilio, \& V. Monno (Eds.), Making strategies in spatial planning. Dordrecht: Springer Netherlands. doi:10.1007/978-90-481-3106-8.

Girard, L.F. (2013). Toward a smart sustainable development of port cities/areas: the role of the 'historic urban landscape approach'. Sustainability, 5(10). doi:10.3390/su5104329.

GUIDEMAPS. (2004). Successful transport decision-making: a project management and stakeholder engagement handbook. Retrieved 14.03.2017 from http://civitas.eu.

Hein, C. (Ed.). (2011). Port cities: dynamic landscapes and global networks. London-New York: Routledge.

Jason Chang, S.K., \& Hsu, Y.T. (2014). Smart travel and sustainable mobility for green transport cities. Retrieved 23.03.2018 from https://newcities.org.

Kim, P., \& Dumitrescu, E. (2010). Share the road: investment in walking and cycling road infrastructure. Retrieved 23.03.2018 from https://www.fiafoundation.org.

Lopez-Ruiz, H., Panayotis. C., Demirel, H., \& Kompi, M. (2013). Quantifying the effect of sustainable urban mobility plans. doi:10.2791/21875.

Mobilna Gdynia. (2017). Retrieved 14.03.2017 from https://www.mobilnagdynia.pl.

Morel, G., Lima, F.R., Martell-Flores, H., \& Hissel, F. (2013). Tools for an integrated systems approach to sustainable port city planning. URBE. Revista Brasileira de Gestao Urbana, 5(2). doi:10.7213/urbe.05.002.SE03.

Polis Network. (2016). Sustainable urban mobility and the smart city. Retrieved 23.03.2018 from https: / /www.polisnetwork.eu.

Przybylowski, A. (2017). Port cities smart \& sustainable development challenges: Gdynia case study. In A. Weintrit \& T. Neumann (Eds.), Safety of sea transportation: marine navigation and safety of sea transportation. London: CRC Press.

Schubert, D. (2011). Seaport cities: phases of spatial restructuring and types and dimensions of redevelopment. In C. Hein (Ed.), Port cities: dynamic landscapes and global networks. London-New York: Routledge.

Studzieniecki, T. (2016). The development of cross-border cooperation in an EU macroregion: a case study of the Baltic Sea Region. Procedia Economics and Finance, 39. doi:10.1016/s2212-5671(16)30318-5. 
The City of Copenhagen. (2015). Copenhagen - City of Cyclists. The Bicycle Account 2014. Retrieved 14.03.2017 from http://www.cycling-embassy.dk.

UN-Habitat. (2017). World Urban Forum. Retrieved 14.03.2017 from https:// unhabitat.org/wuf.

United Nations. (2014). World urbanization prospects: the 2014 revision, highlights. Retrieved 23.03.2018 from https://esa.un.org.

Wefering, F., Rupprecht, S., Bührmann, S., \& Böhler-Baedeker, S. (2013). Developing and implementing a sustainable urban mobility plan. Retrieved 23.03.2018 from http://www.eltis.org.

Wojewnik-Filipkowska, A. (2017). Rationalisation of investment decisions in the sustainable management of urban development - is a new paradigm needed? Problemy Ekorozwoju. Problems of Sustainable Development, 12(1).

Wolek, M. (Ed.). (2016). Gdynia's Sustainable Urban Mobility Plan (SUMP) and its development. Retrieved 23.03.2018 from https://www.mobilnagdynia.pl.

Xiao, Z., Siu Lee Lam, J. (2017). A systems framework for sustainable development of port city: a case study of Singapore's policies. Research in Transportation Business \& Management, 22. doi:10.1016/j.rtbm.2016.10.003.

Zopf, Y. (2017). Global rise of cities poses challenge to sustainable urban development. Retrieved 23.03.2018 from https://www.weforum.org.

\section{Acknowledgements}

Author contributions: author has given an approval to the final version of the article.

Funding: this research was undertaken as part of the Maritime industries in the innovative economy project and was fully funded by a grant (DS/435/2017). 


\section{Appendix}

Table 1.

A new way of planning urban mobility

\begin{tabular}{|c|c|}
\hline Traditional transport planning & Sustainable urban mobility planning \\
\hline focus on traffic & focus on people \\
\hline $\begin{array}{l}\text { primary objectives: traffic } \\
\text { flow capacity and speed }\end{array}$ & primary objectives: accessibility and life quality \\
\hline planning by experts & $\begin{array}{l}\text { planning with the involvement of stakeholders using a transparent and participa- } \\
\text { tory approach }\end{array}$ \\
\hline domain of traffic engineers & interdisciplinary planning teams \\
\hline infrastructure focus & integrated set of actions to achieve cost-effective solutions \\
\hline related to administrative area & related to functioning area based on travel-to-work patterns \\
\hline sectorial planning document & $\begin{array}{c}\text { sectorial planning document consistent and complementary to related policy } \\
\text { areas (land use and spatial planning, social services, health, enforcement and po- } \\
\text { licing, etc.) }\end{array}$ \\
\hline limited impact assessment & $\begin{array}{c}\text { regular monitoring and evaluation of impacts to inform a structured learning } \\
\text { and improvement process }\end{array}$ \\
\hline
\end{tabular}

Source: Wefering et al. (2013).

Table 2.

Typical stakeholder groups involved in transport projects

\begin{tabular}{|c|c|c|c|}
\hline Government/authorities & Businesses/operators & $\begin{array}{c}\text { Communities/local } \\
\text { neighbourhoods }\end{array}$ & Others \\
\hline local authorities & $\begin{array}{l}\text { transport operators/pro- } \\
\text { viders }\end{array}$ & $\begin{array}{c}\text { national environmental } \\
\text { NGOs }\end{array}$ & research institutions \\
\hline neighbouring cities & transport consultants & motorist associations & universities \\
\hline local transport authority & car sharing companies & trade unions & training institutions \\
\hline traffic police & bicycle rental operators & media & experts from other cities \\
\hline other local transport bodies & other mobility providers & local authority forums & foundations \\
\hline other local authority bodies & $\begin{array}{l}\text { national business associ- } \\
\text { ations }\end{array}$ & $\begin{array}{l}\text { local community organi- } \\
\text { sations }\end{array}$ & \\
\hline politicians & major employers & local interest groups & \\
\hline other decision-makers & private financiers & cycle/walking groups & \\
\hline partnering organisations & $\begin{array}{c}\text { international/national } \\
\text { business }\end{array}$ & $\begin{array}{c}\text { public transport user } \\
\text { groups }\end{array}$ & \\
\hline project managers & regional/local business & transport users & \\
\hline professional staff & local business associations & citizens & \\
\hline emergency services & small businesses & visitors & - \\
\hline health \& safety executives & retailers & $\begin{array}{l}\text { citizens in neighbouring } \\
\text { cities }\end{array}$ & \\
\hline European Union & $\begin{array}{l}\text { utility services (e.g. elec- } \\
\text { tric, telecoms) }\end{array}$ & disabled people & \\
\hline ministry of transport & engineers/contractors & landowners & \\
\hline other national ministries & & transport staff & \\
\hline \multirow{2}{*}{ regional government } & \multirow[t]{2}{*}{-} & parents/children & \\
\hline & & older people & \\
\hline
\end{tabular}

Source: GUIDEMAPS (2004). 
Table 3.

\section{ADVANCE method prioritisation selected results}

\begin{tabular}{|c|c|}
\hline Mobility areas and activities & Result \\
\hline ticket integration of public transport & 4.45 \\
\hline city car park & 4.21 \\
\hline inclusion of the pedestrian traffic in project planning & 4.14 \\
\hline public spaces & 4.03 \\
\hline building density and public transport stops & 3.97 \\
\hline park \& ride car parks & 3.79 \\
\hline restrictions on lorries entering the city centre & 3.79 \\
\hline cyclist safety in crossroads & 3.69 \\
\hline passenger information & 3.69 \\
\hline road traffic safety system & 3.69 \\
\hline safe trip to school & 3.62 \\
\hline 'green' vehicles in public transport & 3.59 \\
\hline bike $\&$ ride parking areas & 3.48 \\
\hline free public transport zone & 3.43 \\
\hline public transport safety & 3.38 \\
\hline sustainable mobility promotion among students & 3.31 \\
\hline re-allocation of space to the bicycle traffic & 3.28 \\
\hline calmed traffic zones in housing estates & 3.21 \\
\hline sustainable mobility promotion among inhabitants & 3.14 \\
\hline city bicycle system & 3.14 \\
\hline rationalisation of business trips & 3.07 \\
\hline speed control and road traffic law enforcement & 3.07 \\
\hline super-regional connections in the bicycle system & 2.97 \\
\hline electrical vehicle charging points & 2.96 \\
\hline parking space monitoring system & 2.90 \\
\hline integration of bicycle transport with public transport & 2.83 \\
\hline standards for goods transport and deliveries & 2.83 \\
\hline restricted pollution emissions zones & 2.76 \\
\hline electrical vehicles for businesses & 2.45 \\
\hline bicycles in bus lanes & 2.41 \\
\hline city carpooling concept development & 2.34 \\
\hline preference for environmental vehicles & 2.31 \\
\hline mobility centre or the officer for mobility & 2.21 \\
\hline
\end{tabular}

Source: Own preparation based on Polis Network (2016). 
Table 4.

Strategic objectives of the Sustainable Urban Mobility Plan for Gdynia and political challenges

\begin{tabular}{|c|c|c|c|c|}
\hline $\begin{array}{l}\text { Political challenges/strategic } \\
\text { objectives }\end{array}$ & $\begin{array}{l}\text { Objective l. } \\
\text { attractive } \\
\text { and safe urban } \\
\text { space }\end{array}$ & $\begin{array}{l}\text { Objective } 2 \text {. } \\
\text { safe and effective } \\
\text { transport system }\end{array}$ & $\begin{array}{l}\text { Objective } 3 \text {. } \\
\text { rational transport } \\
\text { choices }\end{array}$ & $\begin{array}{l}\text { Objective } 4 . \\
\text { effective cargo } \\
\text { transport in the city }\end{array}$ \\
\hline $\begin{array}{l}\text { health: how to create } \\
\text { a health-friendly environment } \\
\text { for inhabitants? }\end{array}$ & XXX & XXX & XXX & $\mathrm{X}$ \\
\hline $\begin{array}{l}\text { congestion: how to create an } \\
\text { economically efficient and acces- } \\
\text { sible city? }\end{array}$ & XXX & XXX & XXX & XX \\
\hline $\begin{array}{l}\text { safety: how to ensure a safe } \\
\text { and reliable urban environment } \\
\text { and mobility? }\end{array}$ & XXX & XXX & $\mathrm{XX}$ & XX \\
\hline $\begin{array}{l}\text { participation: how to engage } \\
\text { citizens and other urban mobility } \\
\text { stakeholders? }\end{array}$ & XX & $\mathrm{X}$ & XXX & $\mathrm{X}$ \\
\hline $\begin{array}{l}\text { strategic planning: how to attain } \\
\text { political objectives, while } \\
\text { ensuring that mobility needs } \\
\text { of the society are met? }\end{array}$ & XXX & XXX & $\mathrm{X}$ & XXX \\
\hline $\begin{array}{l}\text { climate change: how to reduce } \\
\text { climate change connected with } \\
\text { transport emissions in the city } \\
\text { and contribute to the fulfilment } \\
\text { of local, national and global } \\
\text { climate change objectives? }\end{array}$ & XXX & XX & $\mathrm{XX}$ & XXX \\
\hline
\end{tabular}

Note:

$\mathrm{X}$ - low importance of the strategic objective to the given political challenge;

$\mathrm{XX}$ - moderate importance of the strategic objective to the given political challenge;

XXX - high importance of the strategic objective to the given political challenge.

Source: Wolek (2016). 
